\title{
Therapy of Malignant Hamster Insulinomas with Monoamine Precursors
}

\author{
J. M. Feldman, Carol Vervaert, Cynthia Klatt, and H. F. Seigler \\ Durham Veterans Administration Medical Center and Departments of Medicine and Surgery, Duke University Medical Center, \\ Durham, North Carolina, USA
}

\begin{abstract}
Summary. The hyperinsulinaemia and hypoglycaemia produced by malignant insulinomas pose a difficult therapeutic problem. The non-polar monoamine precursors 5-hydroxytryptophan, L-3,4dihydroxyphenylalanine and DL-threo-dihydroxyphenylserine are readily taken up by normal hamster pancreatic islets and are converted intracellularly to serotonin, dopamine and norepinephrine. These intracellular monoamines then inhibit glucose-stimulated insulin secretion. In the present study we have determined if the monoamine oxidase inhibitor pargyline, and monoamine precursors, could modify the severe hypoglycaemia of hamsters bearing a rapidly growing transplantable insulinoma. One hour after receiving the respective precursor there was an 11 , 18 , and 54-fold increase in the concentration of serotonin, dopamine or norepinephrine in the insulinomas. Twenty four hours after the administration of the respective precursors there were the following increases in plasma glucose in the respective groups: 5-hydroxytryptophan, $1.9 \pm 0.5$ to $4.9 \pm$ $0.3 \mathrm{mmol} / \mathrm{l}$ (mean \pm SEM); L-3,4-dihydroxyphenylalanine, $1.5 \pm 0.3$ to $3.4 \pm 0.6 \mathrm{mmol} / \mathrm{l}$; and DLthreo-dihydroxyphenylserine, $1.5 \pm 0.2$ to $6.4 \pm 0.7$ $\mathrm{mmol} / \mathrm{l}$. The change in plasma insulin concentration was statistically significant only in the group receiving DL-threo-dihydroxyphenylserine ( $229 \pm 59$ to $81 \pm$ $42 \mathrm{mU} / \mathrm{l})$. To determine if this therapeutic approach could modify the rapidly fatal outcome of the tumour-bearing hamsters, they received $0.154 \mathrm{~mol} / 1$ saline, DL-threo-dihydroxyphenylserine or pargyline plus DL-threo-dihydroxyphenylserine every two days. The survival of the groups (mean \pm SEM) was: saline $8.4 \pm 1.1 \mathrm{~d}$; DL-threo-dihydroxyphenylserine $17.9 \pm 3.5 \mathrm{~d}$; and pargyline plus DL-threo-dihydroxyphenylserine $24.4 \pm 5.5 \mathrm{~d}$. The present study suggests that increasing the monoamine content of malignant insulinomas may favourably modify the course of these devastating tumours.
\end{abstract}

Key words: Insulinoma, monoamine oxidase, hypoglycaemia, norepinephrine, dopamine, serotonin, pargyline, neoplasm, insulin

Benign and non-metastatic malignant insulinproducing islet cell tumours of the pancreas (insulinomas) are usually successfully treated by surgical excision. However, the hyperinsulinaemia and hypoglycaemia produced by metastatic malignant insulinomas presents a more difficult therapeutic problem. Agents used to treat this condition with varying degrees of success have included diazoxide, ACTH, glucocorticoids, human growth hormone, glucagon and streptozotocin [1].

Histochemical fluorescence data indicates that normal pancreatic islets of some species and some insulinomas contain dopamine and serotonin [2,5]. Pharmacological doses of these monoamines inhibit insulin secretion from normal pancreatic islets $[6,7]$. We recently demonstrated that a transplantable malignant islet cell tumour of the golden hamster contains a low concentration of dopamine and norepinephrine and a higher concentration of serotonin $[8,9]$, together with high activity of the monoamine inactivating enzymes monoamine oxidase (monoamine: oxygen oxidoreductase, EC 1.4.3.4.) and catechol-o-methyltransferase (S-adenosyl-Lmethionine: catechol-o-methyltransferase, EC 2.1.1.6.).

Normal hamster pancreatic islets also have high monoamine oxidase (MAO) activity. If this MAO is inhibited with the MAO inhibitor tranylcypromine and the norepinephrine precursor DL-threo-dihydroxyphenylserine (DOPS), the dopamine precursor L-3,4-dihydroxyphenylalanine (L-DOPA) or the serotonin precursor 5-hydroxytryptophan (5-HTP) administered, the concentration of the respective 
monoamine was markedly increased in the pancreatic islets [10]. The increase in islet monoamines was associated with marked inhibition of in vivo and in vitro glucose-stimulated insulin secretion [10].

The purpose of the present study was to determine if the monoamine concentration of insulinomas could be increased by increasing the synthesis of monoamines with monoamine precursors and inhibiting the degradation of monoamines with the MAO inhibitor pargyline. We also wanted to determine if an increase in the concentration of monoamines in the insulinoma would decrease the insulin secretion from the tumour and ameliorate the hypoglycaemia of the hamsters.

\section{Materials and methods}

\section{Materials}

The following chemicals were purchased from commercial sources: DL-threo-dihydroxyphenylserine (DOPS), L-3,4-dihydroxyphenylalanine (L-DOPA), 5-hydroxytryptophan (5-HTP), Sacetyl coenzyme A, N-acetyl-5-methoxytryptamine (melatonin) (Sigma Chemical Co., St. Louis, MO); pargyline HCl (Saber Labs, Morton Grove, IL); tryptamine bisuccinate (side chain-2- ${ }^{14} \mathrm{C}$ ) with specific activity of $60 \mathrm{mCi} / \mathrm{mmol}$ and S-adenosyl-L-( ${ }^{3} \mathrm{H}$-methyl)methionine $\left({ }^{3} \mathrm{H}-\mathrm{SAM}\right)$ with specific activity of 7.5 to $10 \mathrm{Ci} / \mathrm{mmol}$ (New England Nuclear, Boston, MA); Insulin Radioimmunoassay Kits (Amersham Corporation, Arlington Heights, IL); and male golden hamsters (100-125 g) (Engel Laboratory, Inc., Farmersburg, IN).

\section{Experimental Procedure}

The hamster insulinoma was removed from host animals under sterile conditions, minced and transplanted into the SC tissues of the recipient animals. As described below, by 2 weeks after transplantation the insulinoma-bearing hamsters had an elevation in plasma insulin and a fall in plasma glucose levels. Blood samples for glucose and insulin assay were usually obtained from the orbital sinus. Following this procedure there may be a rise in plasma glucose for the next hour. Therefore, the pre-treatment blood samples were obtained 24 to $25 \mathrm{~h}$ prior to the post-treatment samples. When evaluating the MAO activity and monoamine and insulin concentration in the tumour, animals were sacrificed by decapitation and blood from the cervical wound collected into heparin. Preliminary studies indicated that there was no difference in the glucose and insulin concentration in blood obtained by orbital puncture or decapitation. After removal the insulinomas were weighed, cut into multiple pieces and stored in individual vials in the freezer $\left(-30^{\circ} \mathrm{C}\right)$ until analysis.

The hamsters had access to food and water until the time of sacrifice. All medications were administered IP. The dose of drugs administerd was: pargyline $8 \mathrm{mg} / \mathrm{kg}$ body weight; DOPS $120 \mathrm{mg}$ / $\mathrm{kg}$; L-DOPA $65 \mathrm{mg} / \mathrm{kg}$; and 5 -HTP $30 \mathrm{mg} / \mathrm{kg}$. In the acute studies, after blood samples were obtained, the hamsters received either $0.154 \mathrm{~mol} / 1$ saline or pargyline at time 0 . Twenty four hours later they received either saline or a monoamine precursor (DOPS, L-DOPA, 5-HTP). They were sacrificed either 1 or $24 \mathrm{~h}$ after the monoamine precursor was given. In chronic studies, to determine the long term effect of pargyline and monoamine precursors on tumour bearing animals, blood samples were obtained at time 0 . The animals then received $0.154 \mathrm{~mol} / 1$ saline or pargyline IP. Twenty four hours after the start of the experiment they received either saline or DOPS. Forty eight hours after the start of the experiment, blood samples were again obtained. The animals then received saline or pargyline. Immediately afterwards, they received saline or DOPS. Thereafter, orbital blood samples were obtained and saline or DOPS were administered at $48 \mathrm{~h}$ intervals until the animals died from hypoglycaemia. The animals were examined at least once a day.

\section{Analytical Methods}

The insulinomas were homogenised with a ground-glass homogeniser at $3^{\circ} \mathrm{C}$. When MAO activity was determined, the tissue was homogenised in potassium chloride $(11 \mathrm{~g} / 1)$ and the assay performed on the total homogenate. The MAO assay uses ${ }^{14}$-C-tryptamine $(1 \mathrm{mmol} / \mathrm{l})$ as substrate [11]. MAO activity is equal to the amount of ${ }^{14}-\mathrm{C}$-labelled indoleacetaldehyde and indoleactic acid formed. These metabolites were isolated by differential solvent extraction and counted in a liquid scintillation counter. The lower limits of sensitivity are $50 \mathrm{pmol} \mathrm{product} / \mathrm{mg}$ tissue/min. The protein content of the homogenate was determined with a coluorimetric method [12]. The enzyme activity was expressed as pmol product formed/mg of tumour homogenate/min of incubation.

The insulinomas for norepinephrine and dopamine analysis were homogenised in $0.1 \mathrm{~mol} / 1$ perchloric acid and the tissues for serotonin were homogenised in $0.1 \mathrm{mmol} / 1 \mathrm{HCl}$. The perchloric acid homogenate was centrifuged at $4000 \mathrm{Xg}$ and the supernatant analysed for norepinephrine and dopamine. As serotonin binds to particulate matter the serotonin analysis was done on the total $\mathrm{HCl}$ homogenate. The norephinephrine $[13,14]$, dopamine $[15,16]$, and serotonin $[17,18]$ concentrations in the insulinomas were determined with previously described sensitive and specific radioassays in which a ${ }^{3} \mathrm{H}$-labelled methyl group is transferred from ${ }^{3} \mathrm{H}$-S-adenosylmethionine to the monoamine under investigation by a semipurified enzyme. After appropriate insolation, the amount of purified radioactive derivative that was generated was determined in a liquid scintillation counter. The lower limit of sensitivity of the norepinephrine assay was 0.3 to $0.6 \mathrm{pmol}$ norepinephrine/assay tube and there was less than $2 \%$ cross reactivity with dopamine and serotonin or DOPS. The lower limit of sensitivity of the dopamine assay was 1 to 2 pmol dopamine/assay tube and there was less than $3 \%$ cross reactivity with norepinephrine, serotonin or L-DOPA. The lower limit of sensitivity of the serotonin assay was 4 to $8 \mathrm{pmol}$ of serotonin/assay tube and there was less than $1 \%$ cross reactivity with norepinephrine, dopamine or 5-hydroxytryptophan. The monoamine content of the insulinomas is expressed as $\mu \mathrm{mol} / \mathrm{kg}$ wet weight.

Plasma glucose was measured with a glucose analyser (Beckman Instruments, Fullerton, CA) that uses a modified glucose oxidase method [19]. After the insulin was extracted from the insulinomas with acid-ethanol, the acid-ethanol was diluted with an appropriate amount of $0.01 \mathrm{mmol} / 1$ sodium phosphate buffer $(\mathrm{pH}=7.3)$ [20]. Plasma and tumour insulin concentrations were determined with a double antibody radioimmunoassay method [21]. Beef insulin was used as the insulin standard. To minimise the problem that the binding curves for hamster and beef insulin are not perfectly parallel, aliquots of plasma and medium were selected that would fall in the midportion of the standard curve. The plasma insulin glucose rations $(\mathrm{I} / \mathrm{G})$ was calculated to determine if the plasma insulin concentration is appropriate to the plasma glucose concentration [22].

\section{Statistical Methods}

Unless otherwise stated, data are given as mean \pm SEM. The statistical significance of differences between two groups was 
Table 1. Alteration in plasma glucose, plasma insulin and tumour monoamine concentration in insulinoma-bearing hamsters $24 \mathrm{~h}$ after the injection of pargyline and/or a monoamine precursor

\begin{tabular}{|c|c|c|c|c|c|c|c|c|}
\hline \multirow{2}{*}{$\begin{array}{l}\text { Monoamine } \\
\text { precursor }\end{array}$} & \multirow{2}{*}{$\begin{array}{l}\text { Pargy- } \\
\text { line } \\
\text { adminis- } \\
\text { tration }\end{array}$} & \multirow{2}{*}{$\begin{array}{l}\text { Tumour } \\
\text { monoamine } \\
\text { assayed }\end{array}$} & \multicolumn{2}{|c|}{ Tumour monoamine $(\mu \mathrm{mol} / \mathrm{kg})$} & \multicolumn{2}{|c|}{ Plasma glucose $(\mathrm{mmol} / 1)$} & \multicolumn{2}{|c|}{ Plasma insulin (mU/1) } \\
\hline & & & $\begin{array}{l}\text { Pre- } \\
\text { treatment }\end{array}$ & $\begin{array}{l}\text { Post- } \\
\text { treatment }\end{array}$ & $\begin{array}{l}\text { Pre- } \\
\text { treatment }\end{array}$ & $\begin{array}{l}\text { Post- } \\
\text { treatment }\end{array}$ & $\begin{array}{l}\text { Pre- } \\
\text { treatment }\end{array}$ & $\begin{array}{l}\text { Post- } \\
\text { treatment }\end{array}$ \\
\hline 0 & 0 & $c$ & c & c & $2.5 \pm 0.5$ & $2.0 \pm 0.4$ & $299 \pm 52$ & $333 \pm 40$ \\
\hline 0 & + & c & c & c & $3.0 \pm 0.5$ & $3.0 \pm 0.6$ & $233 \pm 79$ & $173 \pm 41$ \\
\hline DOPS & 0 & Norepinephrine & $\begin{array}{c}0.6 \\
(<0.2-2.6)\end{array}$ & $\begin{array}{c}0.3 \\
(<0.2-0.8)\end{array}$ & $2.5 \pm 0.6$ & $5.7 \pm 0.4^{\mathrm{b}}$ & $273 \pm 93$ & $152 \pm 36$ \\
\hline DOPS & + & Norepinephrine & $\begin{array}{c}0.6 \\
(<0.2-2.6)\end{array}$ & $\begin{array}{c}0.6 \\
(<0.2-1.1)\end{array}$ & $1.5 \pm 0.2$ & $6.4 \pm 0.7^{b}$ & $229 \pm 59$ & $81 \pm 42^{a}$ \\
\hline L-DOPA & + & Dopamine & $\begin{array}{c}0.3 \\
(<0.2-1.0)\end{array}$ & $\begin{array}{c}1.3 \\
(<0.2-4.7)\end{array}$ & $1.5 \pm 0.3$ & $3.4 \pm 0.6^{b}$ & $190 \pm 27$ & $151 \pm 38$ \\
\hline 5-HTP & + & Serotonin & $\begin{array}{c}5.2 \\
(<0.6-26.5)\end{array}$ & $\begin{array}{ll} & 5.9 \\
( & 1.3-12.4)\end{array}$ & $1.9 \pm 0.5$ & $4.9 \pm 0.3^{b}$ & $368 \pm 132$ & $188 \pm 35$ \\
\hline
\end{tabular}

Plasma glucose and insulin and tumour monoamine concentration were determined in insulinoma-bearing hamsters before (pre-treatment) and after (post-treatment) the hamsters received the norepinephrine precursor DL-threo-dihydroxyphenylserine (DOPS), the dopamine precursor L-3, 4 dihydroxyphenylalanine (L-DOPA) or the serotonin precursor 5-hydroxytryptophan (5-HTP) 24 h before. Some hamsters were treated with the monoamine oxidase inhibitor pargyline $48 \mathrm{~h}$ before. Values are given as the mean \pm SEM or mean (range) of specimens from 6 to 10 different hamsters. The pre-treatment monoamine concentrations were established on another group of insulinomas obtained from 6 to 8 untreated hamsters

${ }^{\text {a }} \mathrm{p}<0.05$ compared with pre-treatment

${ }^{b} \mathrm{p}<0.01$ compared with pre-treatment

$c$ not measured

sought with Student's $t$ test if only a single determination was made in an animal [23]. If more than one determination was made in an animal the post-treatment value was expressed as a percentage of the pre-treatment and the data analysed by the paired $t$ test [23]. When more than one experimental group was being compared to the control group, the data was subjected to analysis of variance. The significance of the differences between mean values was then estimated with the single-tailed multiple comparisons test of Scheffe [23].

\section{Results}

In a group of 12 normal fed hamsters, the plasma glucose concentration was $6.0 \pm 0.3 \mathrm{mmol} / \mathrm{l}$, the plasma insulin concentration was $48 \pm 7 \mathrm{mU} / 1$ and the plasma insulin glucose ratio was $8.1 \pm 1.3$. Fourteen (range 13 to 15 ) days after receiving a transplantation of the insulinoma, a second group of 12 hamsters had a plasma glucose concentration $4.5 \pm$ $0.4 \mathrm{mmol} / 1(\mathrm{p}<0.05)$, a plasma insulin concentration of $170 \pm 31 \mathrm{mU} / \mathrm{1}(\mathrm{p}<0.05)$ and a plasma insulin glucose ratio of $63 \pm 21(\mathrm{p}<0.05)$ compared with normal group. Twenty one (range 20 to 24 ) days after receiving the transplantation of the insulinoma this second experimental group had the following values: plasma glucose $1.7 \pm 0.3 \mathrm{mmol} / \mathrm{l}$; plasma insulin $230 \pm 43 \mathrm{mU} / 1$ and plasma insulin glucose ratio of $156 \pm 27$. In the absence of therapy the hamsters usually developed hypoglycaemic signs (diaphoresis, seizures) between 24 and 34 days after tumour transplantation.

Table 1 shows attempts to decrease insulin secretion from the insulinomas by increasing the monoamine concentration of the tumour by administering pargyline at $0 \mathrm{~h}$ and DOPS, L-DOPA or 5-HTP $24 \mathrm{~h}$ later. Twenty. four hours after the monoamine precursor, the animals were sacrificed. There was no change in the low plasma glucose and the high plasma insulin concentration in the group receiving saline and in the group receiving pargyline and saline. There was a significant increase in the plasma glucose concentration in the groups receiving DOPS alone, pargyline plus DOPS, pargyline plus L-DOPA and pargyline plus 5-HTP. However, only the pargyline plus DOPS group had a significant fall in the elevated plasma insulin concentration.

At the time of sacrifice the SC insulinoma in the control group weighed $4.4 \pm 0.45 \mathrm{~g}$ and had an insulin content $0.118 \pm 0.029 \mathrm{mU} / \mathrm{g}$. There was no significant difference in the weight or in the insulin concentration of the insulinomas in the other experimental groups. There was $67 \%$ inhibition of MAO in the insulinoma in the animals receiving pargyline (control MAO activity $2331 \pm 158 \mathrm{pmol} / \mathrm{mg} / \mathrm{min}$ and pargyline treated MAO activity $772 \pm 64 \mathrm{pmol} / \mathrm{mg} /$ min). However none of the groups had an increase in 
Table 2. Alteration in plasma glucose and tumour monoamine concentration of insulinoma-bearing hamsters $1 \mathrm{~h}$ after the injection of pargyline and/or monoamine precursors

\begin{tabular}{|c|c|c|c|c|c|c|}
\hline \multirow{2}{*}{$\begin{array}{l}\text { Monoamine } \\
\text { precursor }\end{array}$} & \multirow{2}{*}{$\begin{array}{l}\text { Pargyline } \\
\text { administration }\end{array}$} & \multirow{2}{*}{$\begin{array}{l}\text { Tumour } \\
\text { monoamine } \\
\text { assayed }\end{array}$} & \multicolumn{2}{|c|}{ Tumour monoamine $(\mu \mathrm{mol} / \mathrm{kg})$} & \multicolumn{2}{|c|}{ Plasma glucose $(\mathrm{mmol} / 1)$} \\
\hline & & & Pre-treatment & Post-treatment & Pre-treatment & Post-treatment \\
\hline DOPS & 0 & Norepinephrine & $\begin{array}{c}0.6 \\
(<0.2-2.6)\end{array}$ & $\begin{array}{l}23.6 \\
(21.2-36.4)\end{array}$ & $2.0 \pm 0.3$ & $2.7 \pm 0.4$ \\
\hline DOPS & + & Norepinephrine & $\begin{array}{c}0.6 \\
(<0.2-2.6)\end{array}$ & $\begin{array}{l}29.5 \\
(5.8-52.5)\end{array}$ & $1.8 \pm 0.7$ & $7.3 \pm 2.1^{\mathrm{a}}$ \\
\hline L-DOPA & + & Dopamine & $\begin{array}{c}0.3 \\
(<0.2-1.0)\end{array}$ & $\begin{array}{l}6.1 \\
(1.7-11.9)\end{array}$ & $2.4 \pm 0.5$ & $5.0 \pm 1.8$ \\
\hline 5-HTP & + & Serotonin & $\begin{aligned} & 5.2 \\
&(<0.6-26.5)\end{aligned}$ & $\begin{array}{l}59.3 \\
(34.8-77.8)\end{array}$ & $2.4 \pm 0.6$ & $1.7 \pm 0.6$ \\
\hline
\end{tabular}

Plasma glucose and tumour monoamine concentration were determined in insulinoma-bearing hamsters before (pre-treatment) and after (post-treatment) the hamsters received the norepinephrine precursor DL-threo-dihydroxyphenylserine (DOPS), the dopamine precursor L-3, 4 dihydroxyphenylaline (L-DOPA) or the serotonin precursor 5-hydroxytryptophan (5-HTP) 1 h before. Some hamsters received the monoamine oxidase inhibitor pargyline 24 to $25 \mathrm{~h}$ before. Values are given as the mean \pm SEM or mean (range) of specimens from 6 to 10 different hamsters. The pre-treatment monoamine concentrations were established on another group of insulinomas obtained from 6 to 8 untreated hamsters

${ }^{\mathrm{a}} \mathrm{p}<0.01$ compared with pre-treatment

the concentration of the appropriate monoamine, $24 \mathrm{~h}$ after administration of the monoamine precursors (Table 1).

To determine if the administration of pargyline and monoamine precursors resulted in an initial elevation in the monoamine concentration of the insulinomas pargyline was administered at $0 \mathrm{~h}$ and DOPS, L-DOPA or 5-HTP at $24 \mathrm{~h}$. The animals were sacrificed $1 \mathrm{~h}$ later. At the time of sacrifice, there was an $84 \%$ inhibition of MAO in the insulinoma (control MAO activity $2331 \pm 158 \mathrm{pmol} /$ $\mathrm{mg} / \mathrm{min}$ and pargyline treated MAO activity $377 \pm$ $31 \mathrm{pmol} / \mathrm{mg} / \mathrm{min}$ ). Table 2 demonstrates that DOPS alone resulted in a 43 fold increase in norepinephrine, pargyline plus DOPS in a 53 fold increase in norepinephrine, pargyline plus L-DOPA in an 18 fold increase in dopamine and pargyline plus 5-HTP in an 11 fold increase in serotonin. Only the pargyline plus DOPS group had a significant increase in plasma glucose (Table 2). DOPS alone reduced the plasma insulin from $461 \pm 69 \mathrm{mU} / \mathrm{l}$ to $222 \pm 42$ $\mathrm{mU} / 1(\mathrm{p}<0.05)$.

Figure 1 compares the plasma glucose, insulin and insulin glucose ratio of insulinoma-bearing hamsters receiving saline and hamsters receiving pargyline plus DOPS every $48 \mathrm{~h}$. The plasma glucose concentration was significantly higher and the plasma insulin glucose ration was significantly decreased in the drug treated group from 2 to $8 \mathrm{~d}$. The plasma insulin concentration was significantly lower in the drug treated group at 4 and $8 \mathrm{~d}$. More than half of the animals in the control group died from hypoglycaemia by $10 \mathrm{~d}$ so the graph for their group was not carried beyond $8 \mathrm{~d}$. Although there was an increase in plasma insulin and a decrease in plasma glucose in the PARG/DOPS group between 8 and $10 \mathrm{~d}$ the majority of animals survived. The increase in plasma insulin and decrease in plasma glucose may have been due to progressive growth of the insulinomas.

Figure 2 depicts studies designed to determine if it is essential to administer pargyline plus DOPS to ameliorate the hyperinsulinaemia and hypoglycaemia of insulinoma-bearing hamsters. DOPS alone did not significantly modify the hyperinsulinaemia and hypoglycaemia. When pargyline plus DOPS was administered once at the beginning of the experiment, there was a significant increase in plasma glucose and a significant decrease in plasma insulin and the plasma insulin glucose ratio at $2 \mathrm{~d}$. By $4 \mathrm{~d}$, however, this group did not differ from the control group. In the third experimental group the hamsters received pargyline plus DOPS initially and again at $2 \mathrm{~d}$. On the fourth day they received pargyline but the DOPS was omitted. There was a striking decrease in plasma glucose concentration and a striking rise in plasma insulin concentration and in the plasma insulin glucose ratio. Although the hypoglycaemia and hyperinsulinaemia could be ameliorated by administering pargyline and DOPS on the sixth day the omission of the DOPS on the fourth day was associated with death from hypoglycaemia in three of the seven animals in the group between day four and day six.

The mean survival of the hamsters in the various experimental groups from the time of initiation of injections were: control $8.3 \pm 1.1 \mathrm{~d}$; pargyline plus DOPS with DOPS omitted on the fourth day only, $12.0 \pm 3.6 \mathrm{~d}$; DOPS alone every two days $17.9 \pm$ 

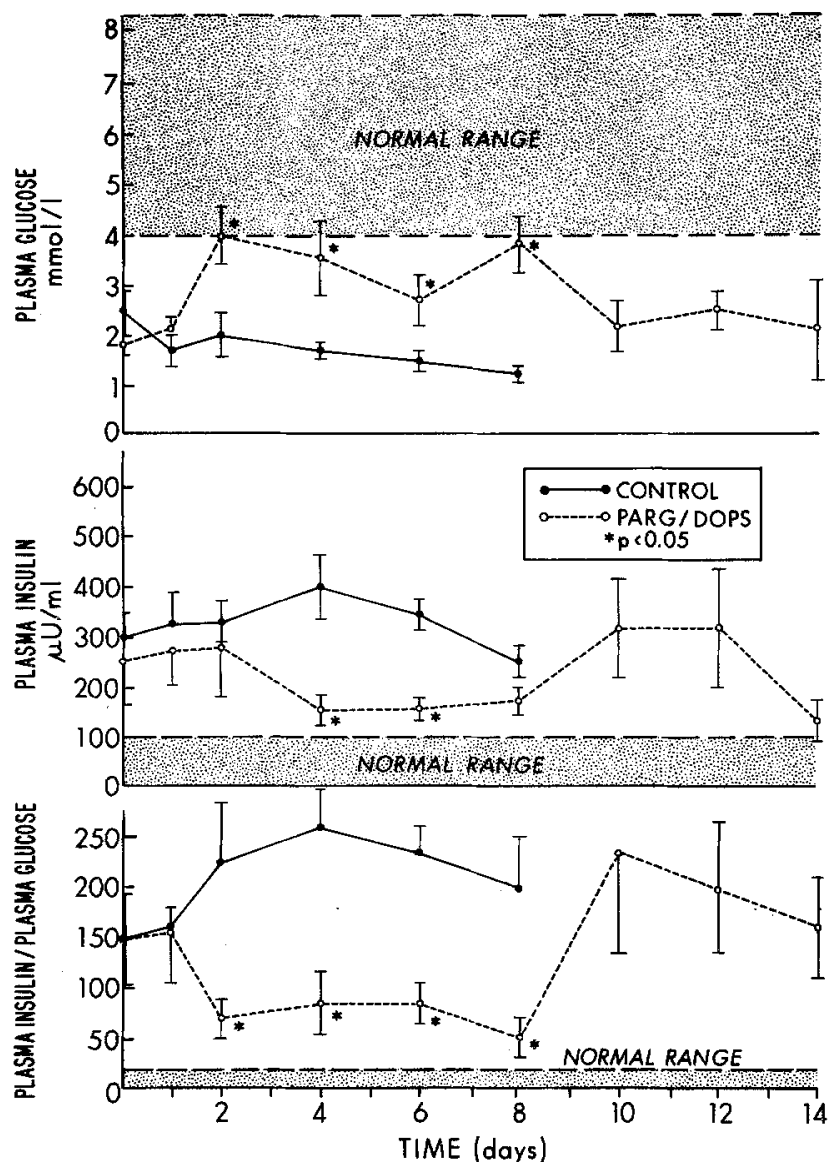

Fig 1. Effect of the administration of pargyline (PARG) and DLthreo-dihydroxyphenylserine (DOPS) on the plasma glucose, insulin and glucose-insulin ratio of insulinoma-bearing hamsters. The PARG/DOPS group initially received pargyline at 0 days and DOPS at one day. Subsequently they received pargyline and DOPS after blood samples were obtained on days $2,4,6,8,10$ and 14. The control group received saline on days $0,1,2,4,6$, and 8 . Initially there was 8 hamsters in the control group and 7 hamsters in the PARG/DOPS group. Each point represents the mean and SEM. The asterisk $(*)$ indicates a significant $(p<0.05)$ difference between the control and PARG/DOPS group
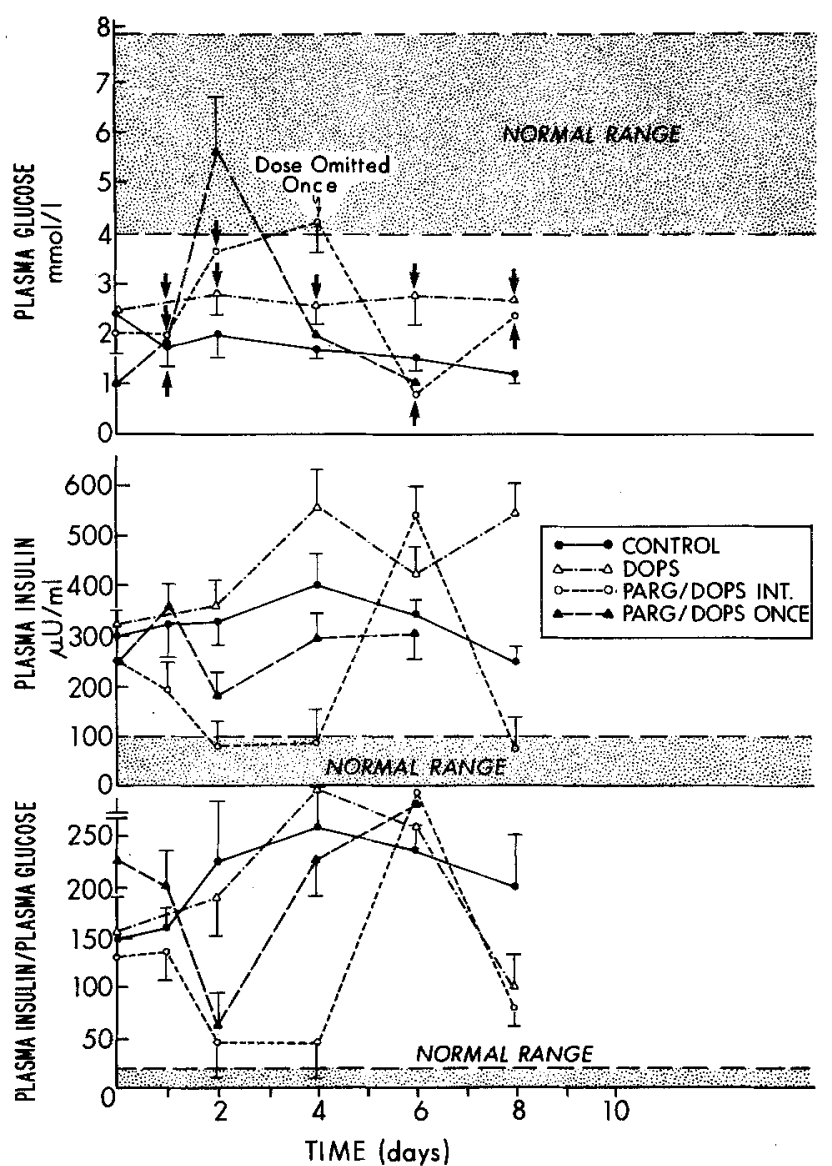

Fig 2. Effect of various dose schedules of pargyline (PARG) and/ or DL-threo-dihydroxyphenylserine (DOPS) on the plasma glucose, insulin and insulin-glucose ratio of insulinoma-bearing hamsters. The PARG/DOPS ONCE and the PARG/DOPS INT (intermittent) received pargyline at 0 days and DOPS at one day. The PARG/DOPS INT continued to receive pargyline and DOPS every two days except on day four when they received only pargyline. The DOPS group received DOPS at $1,2,4,6$ and 8 days. The control group received saline at these times. There were initially 7 or 8 hamsters in each group. Each point represents the mean and SEM. The solid arrow in the panel depicting plasma glucose indicates the time of DOPS administration. The insulin-glucose ratios that exceed the scale of the figure are: DOPS at 4 days 317 ; PARG/DOPS ONCE at 6 days 302; and PARG/DOPS at 6 days 616

$0.9 \mathrm{~g}$. However gross and microscopic examination revealed extensive intra-abdominal deposits of metastatic insulinoma.

\section{Discussion}

In the present study we have demonstrated that the norepinephrine concentration of transplantable hamster insulinomas is increased by the administration of pargyline and DOPS. This was associated with a decrease in plasma insulin concentration, an 
increase in plasma glucose concentration with a resulting decrease but not complete correction of the markedly abnormal insulin glucose ratio. Our data suggests that the increase in plasma glucose is due to inhibition of insulin secretion from the insulinoma. However administration of the dopamine precursor L-DOPA or the serotonin precursor 5-HTP resulted in a statistically significant increase in plasma glucose despite a statistically nonsignificant decrease in plasma insulin. Thus it is possible that extrapancreatic effects may also contribute to the amelioration of the hypoglycaemia by the monoamine precursors. The monoamines may antagonise insulin action in peripheral tissues or stimulate hepatic glycogenolysis or gluconeogenesis. It is also conceivable that the monoamine precursors stimulate the release of hormones such as glucagon, glucocorticoids or growth hormone that are known to antagonise the action of insulin. Finally the monoamine precursors may act as general inhibitors of tumour growth, rather than specific inhibitors of insulin secretion. This is unlikely for the insulinoma growth rate does not seem to be decreased by chronic administration of monoamine precursors.

Although there are occasional insulinomas that are glucose responsive, most benign and malignant human insulinomas do not secrete insulin in response to a glucose challenge [24-27]. The hamster insulinoma has either sluggish or absent insulin secretion in response to a glucose challenge [27, 28]. However, the insulinoma has an adenylcyclase system that can be activated by glucagon [28]. Glucagon, $\mathrm{N}^{6} 0^{2}$ dibutyrl-adenosine $3^{\prime} 5^{\prime}$-monophosphate, potassium and calcium can increase insulin secretion from the hamster insulinoma $[28,29]$. These stimuli are also effective in increasing insulin secretion from normal pancreatic $B$ cells. The exact mechanism by which monoamines inhibit insulin secretion from normal pancreatic B cells or from the hamster insulinoma is not clear at this time.

Previous studies of the effects of catecholamines on insulin secretion from insulinomas have varied depending on the experimental design used. Shen [30] found that an acute infusion of propranolol and epinephrine inhibited insulin secretion in five normal subjects, but did not alter the increased insulin secretion in two patients with insulinomas. Lins and Effendic noted that an epinephrine infusion inhibited glucose-stimulated insulin secretion in patients harbouring glucose responsive insulinomas [27]. However, epinephrine did not inhibit glucagon-stimulated insulin secretion from insulinomas. Scandellari et al found that chronic propranolol administration ameliorated the hypoglycaemia of patients with insulinomas [31]. Propranolol did not alter the increased levels of plasma insulin in the basal state suggesting it was acting by an extra pancreatic mechanism. However, it did decrease the insulin response to a challenge with glucose, tolbutamide or glucagon.

The approach used in the present study differs in a number of respects from approaches used in the past. Monoamines such as epinephrine are polar compounds that do not penetrate cell membranes well $[7,32]$. Such "exogenous" monoamines probably inhibit insulin secretion by acting at the cell membrane. There is pharmacological evidence that non-polar monoamine precursors such as DOPS, LDOPA and 5-HTP effectively penetrate the cell membrane. Intracellularly they are converted to their respective "endogenous" monoamines. It is in this location that they may inhibit insulin secretion [7, 32].

The present animal study suggests that it may be worthwhile to try to ameliorate the hypoglycaemia of patients with malignant insulinomas by utilising monoamine precursors and/or inhibitors. We selected DOPS and pargyline for long term evaluation for several different reasons. Some animals who received pargyline and L-DOPA or 5-HTP acutely, became hyperkinetic, due probably to increased brain monoamine levels. In contrast, the animals who received pargyline and DOPS acutely, did not have any change in behaviour. The threo-isomer of DOPS used in these studies does not penetrate the central nervous system well and so does not increase the concentration of norepinephrine in the brain [13]. In the acute studies, DOPS also seemed to be a more effective inhibitor of insulin secretion from the insulinoma than L-DOPA or 5-HTP. However, there are species difference in the response of the $\mathrm{B}$ cells to stimulators and inhibitors of insulin release [33]. Thus L-DOPA may be as effective in ameliorating the hypoglycaemia of patients with insulinoma than is DOPS. L-DOPA has been given in conjunction with the MAO inhibitor deprenyl to increase the dopamine concentration in the basal ganglia of the brain of patients with Parkinson's Disease [34]. Perhaps drugs such as these might ameliorate the hypoglycaemia of patients with nonresectable insulinomas.

Acknowledgements. This study was supported by the Medical Research Service of the Veterans Administration and NlH Chinese Hamster Program Project 1 PO 1 AM 21922-01.

\section{References}

1. Cunningham GR, Quickel KE Jr, Lebovitz HE (1971) The use of insulin dynamics in the evaluation of streptozotocin therapy of malignant insulinomas. J Clin Endocrinol Metab 33: $530-536$ 
2. Cegrell L (1968) The occurrence of biogenic monoamines in the mammalian endocrine pancreas. Acta Physiol Scand [Suppl] 314: 1-60

3. Cegrell L (1970) Dopamine in a human islet cell carcinoma metastasis. Acta Pathol Microbiol Scand 78: 734

4. Van der Sluys Veer J, Choufoer JC, Querido A, Van der Heul RO, Hollander CF (1964) Metastasizing islet cell tumour of the pancreas associated with hypoglycaemia and carcinoid syndrome. Lancet I: 1416-1419

5. Dayan AD (1967) Absence of catecholamines from islet cells of human pancreas and a $\beta$-cell tumor in man. Acta Histochem (Jena) 28: 186-189

6. Lebovitz HE, Feldman JM (1973) Pancreatic biogenic amines and insulin secretion in health and disease. Fed Proc 32: 1797-1802

7. Feldman JM, Lebovitz HE (1972) A serotoninergic mechanism for the control of insulin secretion. Trans Assoc Am Physicians 85: 279-294

8. Grillo TAI, Whitty AJ, Kirkman H, Foa PF, Kobernick D (1967) Biological properties of a transplantable islet-cell tumour of the golden hamster I. Histology and histochemistry. Diabetes 16: 409-414

9. Feldman JM, Reintgen DS, Seigler HF (1979) Monoamine oxidase and catechol-o-methyltransferase activity in hamster and rat insulinomas. Diabetologia 17: 249-256

10. Zern RT, Bird JL, Feldman JM (1980) Effect of increased pancreatic islet norephinephrine, dopamine and serotonin concentration on insulin secretion in the golden hamster. Diabetologia 18: 341-346

11. Wurtman RJ, Axelrod J (1963) A sensitive and specific assay for the estimation of monoamine oxidase. Biochem Pharmacol 12: $1439-1441$

12. Lowry OH, Rosenbrough NJ, Farr AL, Randall RJ (1951) Protein measurements with the Folin phenol reagent. J Biol Chem 193: 265-275

13. Feldman JM, Henderson JH, Blalock JA (1979) Effect of pharmacological agents and fasting on pancreatic islet norepinephrine in the golden hamster. Diabetologia 17: 169-174

14. Henry DP, Starman BJ, Johnson DG, Williams RH (1975) A sensitive radioenzymatic assay for norepinephrine in tissues and plasma. Life Sci 16: 375-384

15. Zern RT, Foster LB, Blalock JA, Feldman JM (1979) Characteristics of the dopaminergic and noradrenergic systems of the pancreatic islets. Diabetes 28: 185-189

16. Coyle JT, Henry D (1973) Catecholamines in fetal and newborn rat brain. J Neurochem 21: 61-67

17. Bird JL, Wright EE, Feldman JM (1980) Pancreatic islets - a tissue rich in serotonin. Diabetes 29: 304-308

18. Saavedra JM, Brownstein M, Axelrod J (1973) A specific and sensitive enzymatic-isotopic microassay for serotonin in tissues. J Pharmacol Exp Ther 186: 505-515

19. Saifer A, Gerstenfeld B (1958) Photometric micro determination of blood glucose with glucose oxidase. J Lab Clin Med 5: $448-460$
20. Scott DA, Fisher AM (1938) The insulin and zinc content of normal and diabetic pancreas. J Clinic Invest 17: 725-729

21. Hales CN, Randle PJ (1963) Immunoassay of insulin with insulin antibody precipitate. Biochem J 88: 137-146

22. Grunt JA, Palotta JA, Soeldner JS (1970) Insulinoma and blood sugar, serum insulin and free fatty acid interrelationships. Diabetes 19: 122-126

23. Zar JH (1974) Biostatistical analysis. Prentice Hall, Englewood Cliffs NJ, p 130-143, 159-161

24. Powers LA (1969) A glucose-responsive adenoma. JAMA 893-896

25. Steinke J, Soeldner JS, Renold AE (1963) Measurement of small quantities of insulin-like activity with rat adipose tissue: IV Serum insulin-like activity and tumour insulin content in patients with functioning islet-cell tumours. J Clin Invest 42: 1322-1329

26. Adcock K, Austin M, Duckworth WC, Solomon SS, Murrell LR (1975) Human islet cell adenoma: metabolic analysis of patient and tumour cells in monolayer culture. Diabetologia 11: $527-534$

27. Lins P, Efendic S (1979) Response of patients with insulinoma to stimulators and inhibitors of insulin release that have been linked with cyclic adenosine monophosphate. Diabetes 28: 190-195

28. Shapiro S, Sumiya E, Fleischer N, Baum SG (1975) Regulation of in vitro insulin release from a transplantable Syrian hamster insulinoma. Endocrinology 97: 442-447

29. Shapiro S, Kaneko Y, Baum SG, Fleischer N (1977) The role of calcium in insulin release from hamster insulinoma cells. Endocrinology 101: 485-493

30. Shen S (1975) Disordered glucose and insulin metabolism in patients with insulinoma. Arch Intern Med 135: 668-672

31. Scandellari C, Zaccaria M, DePalo C, Erle G, Federspil G (1978) The effect of propranolol on hypoglycaemia. Observations in five insulinoma patients. Diabetologia 15: 297-301

32. Wilson JP, Downs RW, Feldman JM, Lebovitz HE (1974) Beta cell monoamines: further evidence for their role in modulating insulin secretion. Am J Physiol 227: 305-312

33. Feldman JM (1979) Species variation in the islets of Langerhans. Diabetologia 16: 1-4

34. Lees AJ, Kohout LJ, Shaw KM, Stern GM Elsworth JD Sandler M, Youdin MBH (1977) Deprenyl in Parkinson's disease. Lancet II: 791-795

Received: April 15, 1980,

and in revised form: October 6, 1980

Jerome M. Feldman, M.D.

Box 2963

Duke University Medical Center

Durham, NC 27710

USA 